complexes of insect variety on one hand and climatic variety on the other; and the task of analysis and synthesis of their inter-relations is almost Herculean.

Until recently, meteorologists had the advantage in that most of their factors could be easily expressed numerically as measurements and so lent themselves to mathematical treatment. It is one of the main tasks of the entomologist in the near future to convert as many as possible of his observations into measurements. The day has come when expressions of the type "not quite so common" or "rather more abundant" must be replaced by terms comparable in accuracy to the meteorological records with which we wish to correlate them. But the task is by no means easy, and many experiments and many mistakes will have to be made before anything like success can be achieved.

It is interesting to speculate as to whether there is more hope of progress by analysing and simplifying the problem into its component parts in controlled laboratory experiments; or by tackling the whole complex of observations in the field! In this connexion it may be noted that the whole tendency of field experiments in agriculture in the last twenty-four years has been away from extreme simplification, and towards greater complexity. It has been found that, if sufficient facts are available, the complex data can be analysed by statistical methods, and more information can be obtained in a shorter period, particularly on the problem of inter-relations of one factor with another, which are eliminated by extreme simplification.

Undoubtedly more progress has been made in the past by studies under laboratory conditions, but the application of the laws and principles so discovered back again to problems in the field has been disappointing.

My own feeling is that-whatever the difficultieswe must study the insects so far as possible in the field under natural conditions; and experiments and field observations were started at Rothamsted about ten years ago with this in view. A standardized light trap was put out into one position in a field and was used to catch insects for more than 1,400 consecutive nights in four years. The number of insects captured each night was used as a basis for correlation with miteorological factors. The field observations were unfortunately brought to an end by the War, but from the thousands of figures already obtained we have been able to get measurements of the effect of most of the principal meteorological factors both singly and in combination with others. Finally, we have been able to forecast the general level of insect abundance from the weather conditions of the previous months. As an example of this, the accompanying diagram shows the correspondence between observed and calculated abundance of insects at Rothamsted for forty-eight consecutive months; the calculated figures being based on two multiple regression formulæ, one for the winter months, and one for the summer. The mathematical analysis showed that, under the climatic conditions of the area, rainfall is the determining factor of insect abundance in the summer, and temperature in the winter; a result which is obviously sound in a district where the rainfall is more or less constant throughout the year while the temperature varies from low in winter to high in summer.

But, of course, the problem must be attacked from all sides and progress will be made from all directions, if only accuracy of measurement can be brought into the biological side. The problem is essentially a mathematical one, and the accuracy of the results will depend on the absence of vagueness in the original observations.

The joint meeting of the Royal Meteorological Society and the Royal Entomological Society, after hearing short papers by Major H. C. Gunton, Dr. C. B. Williams, Dr. A. E. Slater and Dr. B. P. Uvarov, and an interesting general discussion, passed resolutions emphasizing the need for more bio-climatic work on insects and the need for further training of economic entomologists in the principles of meteorology. It was also suggested that other biological societies should take some share in responsibility for the production of the annual Phenological Report, at present sponsored entirely by the Royal Meteorological Society.

\section{WEATHER AND ELECTRIC POWER SYSTEMS}

$\mathrm{A}$ JOINT meeting of the Institution of Electrical Engineers and the Royal Meteorological Society was held on October 18 to discuss the effects of weather on electric power supply systems.

The meeting was opened by four short papers, two by Mr. J. S. Forrest and Mr. H. W. Grimmitt presenting the subject from the point of view of the electrical engineer, and two by Mr. A. J. Drummond and WingCommander R. M. Poulter describing the meteorological point of view. In the ensuing general discussion, the following speakers took part: Mr. C. K. M. Douglas, Mr. R. A. S. Thwaites, Dr. J. Glasspoole, Mr. E. B. Powell, Mr. E. G. Dymond, Mr. G. Manley, Mr. C. G. Carrothers, Mr. J. F. Shipley, Mr. E. E. Hutchings, Mr. W. Hill, Mr. C. T. Melling, Mr. W. N. C. Clinch, Mr. P. Schiller, and Mr. G. W. N. Cobbold.

In the course of the meeting, a demonstration was given of the radio-sonde, and other meteorological instruments operating on electrical principles. The main features of the discussion are summarized here.

In general, weather affects power systems in two ways : it causes variations in the load on the plant, and it may, under abnormal conditions, cause actual damage to equipment and an interrupticn of supply.

\section{Load Variations Due to Weather}

The lighting load is mainly a function of the daylight illumination, while the heating load is deter. mined largely by the air temperature, and, to a lesser extent, by the wind velocity and relative humidity. The heating load requires serious consideration as it may amount to a significant proportion of the total load. For example, in the case of the south-east England electricity supply system, the peak load on two winter days, only a week apart, was found to differ by 22 per cent, which was $400,000 \mathrm{~kW}$., owing to a drop of $25^{\circ} \mathrm{F}$. in the mean air temperature.

Many supply engineers have derived empirical relationships between load and temperature, and between load and daylight illumination. In this way, they are able to predict, within a few per cent, the effect which changes in temperature or illumination will have on the load. In addition, three-dimensional models have been prepared in order to study the correlation between load, temperature, and illumination. There is, however, scope for further work on this subject. 


\section{Breakdowns Due to Abnormal Weather}

Power system plant, particularly if installed outdoors, is liable to break down electrically, or to sustain mechanical damage under abnormally severe weather conditions. The insulation of overhead lines and substations may flash over owing to moist conducting films deposited on the surface by fog and atmospheric pollution. Thunderstorms frequently cause breakdown of insulation, and in the case of overhead lines, lightning is responsible for about 60 per cent of the total number of breakdowns. It is also the cause of a large proportion of transformer failures. In order to obtain data on thunderstorms, the Central Electricity Board has installed thunderstorm recorders in various parts of Great Britain. These instruments make a continuous record of atmospherics, and give an indication of the distance and the severity of the storm. The records obtained are correlated with the breakdowns due to lightning on the power system.

Ice storms of various types may cause extensive mechanical damage to overhead lines. Fortunately, such storms are not common, and during the last twenty years have occasioned only about ten major breakdowns in Britain. The most dangerous weather conditions are those which lead to a heavy deposit of ice on the overhead-line conductors. The ice may be in the form of frozen sleet, rime, or glazed frost. Such deposits are formed if the surface air and the conductor temperatures are just below freezing point, and liquid precipitation, which may be supercooled, falls from a relatively warm layer above the cold surface air. The most frequent type of damage is conductor breakage due, either to the conductors coming into contact with each other and being burnt through by the resulting short-circuit current, or to pure tensile failure under the weight of ice. Under very severe conditions, cross-arms may be broken, and steel towers buckled. The worst ice storms in Britain in recent years occurred in 1933, when sleet caused extensive damage in South Wales and other districts, and in 1940 when conditions giving rise to a belt of glazed frost about forty miles wide persisted for several days. In both cases, heavy ice deposits up to 5 in. diameter accumulated on overhead-line conductors. In 1937, damage was caused locally in North Wales and in the Pennine area owing to the combined effects of ice deposit and high wind.

The Electricity Commissioners' regulations specify certain minimum requirements for the construction of overhead lines, but the supply engineer may, if he considers it necessary, construct lines with a higher factor of safety, and it is on this question that guidance from meteorologists is useful. It would also be of assistance to the overhead-line engineer if the meteorologist could indicate which parts of a country are likely to be immune from ice storms.

\section{Weather Statistics}

Data on past weather are required for correlation with load variations and plant breakdowns, and as a basis for the design of new equipment, particularly for outdoor operation. The electrical engineer has therefore frequently to make use of the meteorologist's data on air and soil temperatures, solar radiation, wind velocities, thunderstorms, frost, fog, relative humidity and atmospheric pollution. Precipitation data are of primary importance to the hydro-electric engineer. It is considered that weather statistics should be objective. Thus, daylight illumination expressed in foot-candles is more likely to be useful than subjective estimates of visibility and cloudiness, and there would seem to be some scope for the development of a standard method of measuring daylight illumination.

Weather data can be obtained from the Daily Weather Report, the Monthly Weather Report, and the various standard books of averages issued by the Meteorological Office. Rainfall maps to a scale of 2 miles to 1 inch have recently been prepared for the North of Scotland Hydro-Electric Board, and maps of this scale are now available for the whole of Britain. Progress has been made in obtaining data on the frequency of occurrence of heavy falls of rain, and observations taken at Kew Observatory have shown that the standard rate of precipitation adopted for wet tests on insulators, $3 \mathrm{~mm}$. per minute, is only likely to occur once in ten years. Work is also being carried out on evaporation and run-off, and on wind data required for wind-power plant. The Meteorological Office is now engaged in the preparation of a climatological atlas of the British Isles which will give not only the means, but also the extremes and frequencies of occurrence of the main meteorological elements.

There is an increasing tendency to utilize electrical methods in deriving statistics of thunderstorms. Thus, point discharge observations and records of radio atmospherics can be used as a measure of the severity and frequency of occurrence of thunderstorms. Electrical devices can be used to count the lightning flashes within a given distance.

\section{Weather Forecasting}

Weather forecasts are required by power system operators in order to assist in preparing loading and maintenance programmes, and in taking precautions against damage due to abnormally severe weather. Such precautions include the circulation of heavy currents through transmission lines in order to prevent the formation of ice deposits, and the provision of alternative routes of supply when thunderstorms are imminent. It is essential that the forecasts should have a high degree of accuracy, and if the weather situation changes after the forecast has been issued, the original forecast should be cancelled immediately. Forecasts of ice storms, thunderstorms, and sudden falls in temperature are the most important.

The forecasting of ice storms which are liable to endanger overhead lines presents a difficult problem. The conditions which give rise to these storms are exceptional, and the formation of adherent ice deposits depends on the temperatures of the conductors, the surface air, and the upper air being within certain rather narrow limits; a very accurate forecast of surface and upper air temperatures, and also of wind velocity, would be required.

The technique of thunderstorm forecasting is relatively well-developed. Two methods are employed, the first being the radio method, which is based on the fact that atmospherics are produced by lightning flashes. The reception of atmospheries thus gives definite evidence of the existence of a thunderstorm, and the approximate location of the storm can be determined from the amplitudes or from the bearings of the atmospherics received at different sites. The development of the storm can be followed, and some hours warning can be given of the probable outbreak of the storm in a certain district. The second and more usual line of attack consists in taking upper-air soundings to determine the stability or instability of the atmosphere. Observations of the pressure, temperature, and humidity up to heights of $70,000 \mathrm{ft}$. 
are obtained from radio-sonde ascents, and are immediately plotted on a temperature-entropy diagram (tephigram). By comparing the observed results with the saturated adiabatics and dew-point lines on the tephigram, it is possible to forecast the vertical cloud development, and to estimate the probability of conditions occurring which will give rise to thunderstorms. It is of interest to note that the radio-sonde transmitter at present used for this work in Britain weighs just over $3 \mathrm{lb}$., and has a range of more than 150 miles; the radiated power is about $40 \mathrm{~mW}$. at a frequency of $27 \mathrm{Mc} . / \mathrm{s}$.

In the case of sudden falls in temperature, a reasonably accurate forecast can be given, but only for a day or so ahead. Long-range or seasonal forecasting is not yet possible in Great Britain, but during the war years considerable advances have been made in the accuracy of short-period forecasts and warnings. There seems to be a need in the electricity supply industry for an accurate and specific 6-hour or 12-hour forecast, and it is considered that there is room for closer collaboration between the meteorological services and the power system control centres. It may not be possible for these services to issue forecasts which are sufficiently local to fulfil all the requirements of the supply engineer, and it is suggested that the most efficient scheme would be for the supply authority to employ a meteorologist who had a knowledge buth of the local weather features, and of the special characteristics of the electricity system. Such a meteorologist could obtain hourly weather reports from the teleprinter network of the Meteorological Office, and could utilize these in the preparation of his own local forecast.

Closer co-operation between meteorologists and electrical engineers should be mutually beneficial ; for the engineers may supplement the meteorologists' data, and may also assist in the development of the highly specialized electrical and radio methods which are now being employed in meteorology.

\section{J.S. FORREST.}

\section{DEVELOPMENT OF A CHEMO- THERAPY FOR SYSTEMIC ARSENICAL POISONING}

\author{
By DR. J. F. DANIELLI, MARY DANIELLI \\ and P. D. MITCHELL \\ Department of Biochemistry, Cambridge \\ AND \\ L. N. OWEN and G. SHAW \\ Department of Organic Chemistry, Imperial College, \\ London
}

CTUDIES by G. R. Cameron and his colleagues had shown by 1942 that in systemic lewisite poisoning a condition prevails in the first few days which in some particulars resembles traumatic shock, being marked by hæmo concentration. It was found that administration of plasma, or of other fluids, was of no avail in reducing the mortality caused by a given dose of lewisite. It was therefore decided that the first step in the treatment of lewisite poisoning must be the inactivation of at least that part of the arsenical causing shock.

The first aim, therefore, was to find the site of damage to the blood capillaries, that is, the site of abnormal loss of protein from the circulation. To facilitate this, a serum albumin was prepared which was tagged by allowing it to react with the diazonium hydroxide of a dye of the trypan blue type. This gave a blue serum albumin, movements of which in the body could readily be followed by the colour. The phrysical properties of this albumin (solubility, osmotic pressure, electrical charge, titration curve, specific viscosity, and molecular weight) were very little different from those of the original albumin. With its use we found that when lewisite is painted on to the skin of a rabbit, the subsequent hæmo concentration is preceded by an increase in the rate of loss of albumin from the blood to about twice the normal value. There is a considerable loss of plasma in the region contaminated by lewisite, but this does not account for more than a small fraction of the increased rate of loss of albumin from the circulation. Most of the increased rate of loss occurred at sites widely distributed through the body, the loss in the skeletal muscles and viscera being particularly marked ${ }^{1,2}$.

It was therefore concluded that a drug was required with the following properties: (1) It shall be able to reach the whole vascular system. (2) It shall be sufficiently non-toxic to eliminate the possibility of dangerous complications if an overdose is given. (3) It shall prevent arsenicals penetrating from the blood-stream into cells. (4) It shall remove arsenicals from cells into which they have penetrated. (5) The product of reaction between the drug and the arsenical shall be readily excreted.

It should be emphasized that these conclusions were based, as were the subsequent experiments, on consideration of complete physiological units, and not on, for example, consideration of enzyme systems. Voegtlin had shown that glutathione would protect cells against the action of arsenicals, and Peters, Stocken and Thompson ${ }^{3}$ had in 1940 shown that 1:2 dithiols have a protective action against lewisite which is exerted through the affinity of the vicinal SH groups for arsenic. Dithioglycerol $(B A L)$ will prevent vesication and systemic poisoning if applied quickly, but is too toxic to be given in large doses, so that it does not fulfil all the requirements given above. We therefore sought a detoxicated thiol, using the principle' that detoxication and renal excretion are both enhanced by reducing the ease with which a substance can penetrate into cells. This reduction can be achieved by introducing polar groups, such as $\mathrm{OH}$ or $\mathrm{COOH}$, into the molecule, thereby satisfying requirements 2 and 5 . In theory, such a detoxicated thiol could be given intravenously in large amounts and, apart from renal excretion, would remain in the bloud and intracellular fluids, penetrating into cells only very slowly, thereby satisfying requirement $\mathrm{I}$. This thiol, being present in high concentration in the blood, would trap any arsenic in the blood and prevent its penetration into cells. Moreover, although the detoxicated thiol may be unable to diffuse into cells, yet the intracellular arsenic must be partly dissociated and so able to diffuse out of cells into the blood, where it would be trapped by the thiol. It was therefore plain that modification of the structure of thiols in the light of our knowledge of cell permeability would give a therapeutic agent satisfying all the requirements 1 to 5 .

Accordingly, two of us (L. N. O. and G. S.) undertook the synthesis of some substances with these properties. In a few months, several such thiols became available, so that it was possible to test the therapeutic activity of glutathione, a number of thiol 